\title{
Environmental Administration of Solid Waste in Baquba City and its Role in Achievement of Economic Development Ass Lecture
}

\author{
Sameer Mahdi Salih* \\ University of Diyala, College of Education for Human Sciences, Department of Geography \\ *Corresponding Author \\ Sameer Mahdi Salih \\ Article History \\ Received: 20.11.2019 \\ Accepted: 27.11 .2019 \\ Published: 09.12.2019
}

\begin{abstract}
Solid waste poses one of the greatest challenges facing developed and developing societies alike in its collection, transport and disposal, as it has a direct relationship with population and development. The objective of this research is to put investment theme in the field of recovery of resources and the establishment of industries revolving in the city of Baquba and the development of environmental, health, economic and social aspects of it. The research dealt with three topics, the first of which deals with the theoretical framework in terms of research problem and hypothesis. In Baquba. The third section dealt with a historical overview of solid waste and the definition of solid waste and the types of waste and their own identity and management of solid urban waste and factors affecting solid waste and methods of solid waste treatment put in the cities rate was selected as the model for the management of waste and economic development in the city of Baquba.
\end{abstract}

Keywords: Environmental Administration, Baquba, Economic Development.

\section{INTRODUCTION}

Solid wastes in the materials that accompanied man through the ages and is a source of pollution of the urban environment and consists in the simplest form of food processing waste and ash resulting from the work of heating, bakeries and kitchens, as well as worn clothes and debris tools, utensils, furniture and building materials.

As a result of the high population density in urban residential areas, new sources of waste production such as shops, institutes, institutions and factories have been added. It has been impossible to adapt to the accumulation of these wastes within residential areas. Therefore, regular solid waste disposal services have been in existence for over 100 years. Countries that have advanced industrially to prevent their accumulation and in line with public health requirements that have grown in importance at the time.

The negative impacts of solid wastes are not limited to deformation and ugliness caused by the landscape, urban environmental degradation, public health hazards represented by the multiplication of disease vectors (insects and rodents) and the health risks of workers in collection, transport and disposal, as well as pollution of water, air and soil. No matter how wasted the resources are, if they are not utilized properly in accordance with the requirements of achieving sustainable development [1].

\section{The first section}

First: The research problem

The problem of research can be identified by the following questio

Does the collection and recycling of solid waste contribute to the different development programs of Baquba Does the sound environment of solid waste of all kinds contribute to the spatial development of the city of Baquba

\section{Second: The research hypothesis}

Scientific hypotheses are determined for research in

Copyright @ 2019: This is an open-access article distributed under the terms of the Creative Commons Attribution license which permits unrestricted use, distribution, and reproduction in any medium for non commercial use (NonCommercial, or CC-BY-NC) provided the original author and source are credited. 
1- There are administrative, technical and material reasons that led to the deterioration of the system of solid waste management in the city of Baquba.

-2It is possible to adopt development policies that will encourage investment in the establishment of recycling industries in the city of Baquba.

\section{RESEARCH AIMS}

The research aims

- Display the subject of investment theme in the field of recovery of resources and the establishment of industries revolving in the city of Baquba.

- Development of the environmental and health side in the city of Baquba.

- Developing the economic and social aspects through the provision of raw materials and cheap prices in the local market.

\section{Limits of research}

Spatial Boundaries: The research dealt with the city of Baquba, the center of Baquba district, center of Diyala province as the province represents the eastern part of central Iraq.

The district occupies the southwestern part of the governorate and the city of Baquba is located in the northern part of the district between two latitudes (-33.39 - 33.47) north and longitude (-44.35 - 44.40) east map [1].

A city locates north of the capital Baghdad, a distance of $63 \mathrm{~km}$, one of the hubs for transport important in linking the center of Iraq's northern dividing (Kurdistan region) as it bordered the road Baquba - Khalis - Kirkuk - the Kurdistan region, increasing the importance of its location and occupy the city [2] within its borders The municipality for the year 2013 area (4690) hectares [3].

\section{The concept of economic development}

Researchers differed in the consideration of development, some of which are seen to mean evolution and some are seen as a multifaceted process that occupies fundamental changes in the economic and social structure and trends adopted by national institutions in the field of production and aims to increase economic growth and reduce inequality.

Map (1) Location of the study area

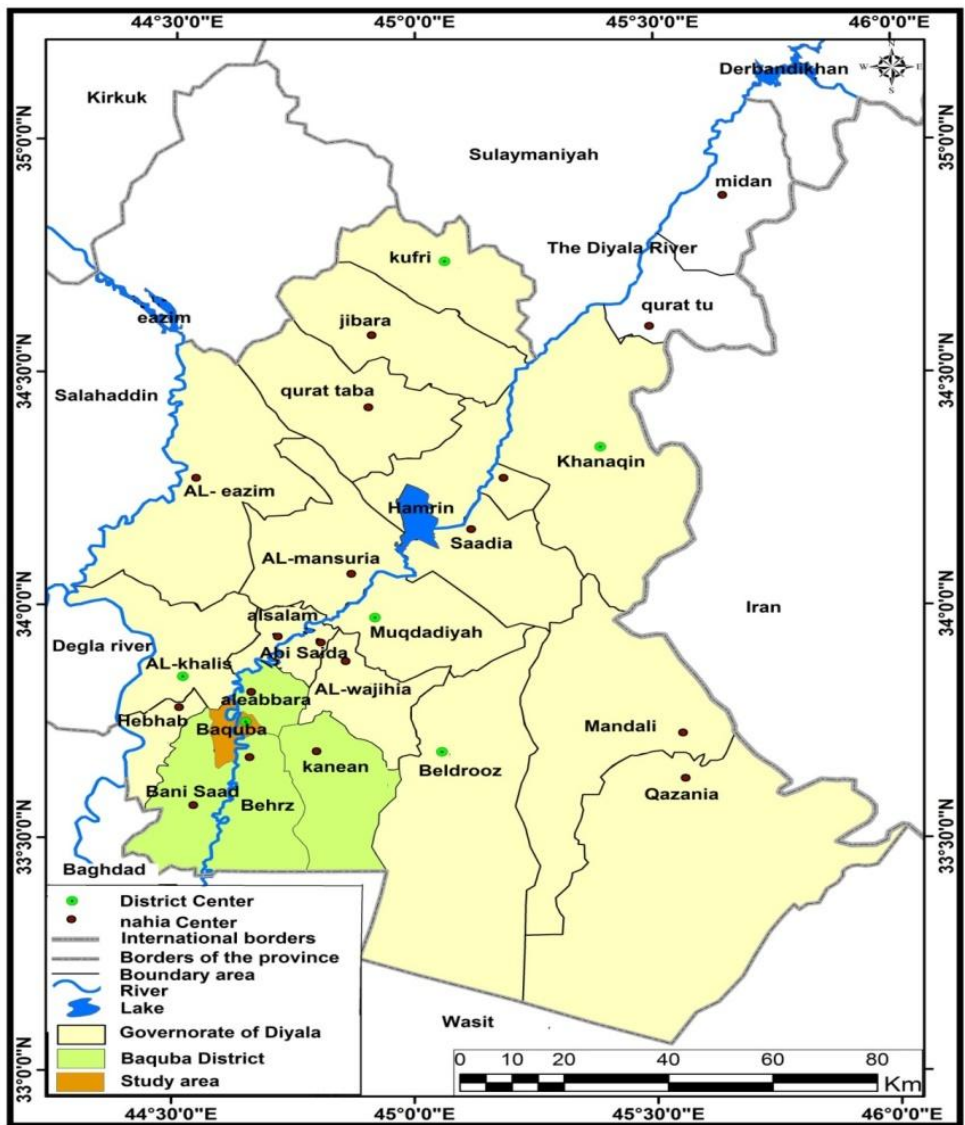

Source: The work of the researcher based on the administrative map of Iraq, the General Authority for Survey, Baghdad 2006, on a scale scale of $1: 1000000$. 
And get rid of absolute poverty and then It may not achieve economic growth in all cases [3]. It is also defined as the process by which a comprehensive and continuous change is accompanied by an increase in the average real income, an improvement in the distribution of income for the benefit of the small class, an improvement in the quality of life and a structural change in production [4].

The concept of development has also shifted from economic growth only to reducing income inequality, achieving equity in income distribution, eliminating poverty, expanding employment opportunities and satisfying basic needs, in addition to economic growth. This has led to an increasing number of economists and policy makers abandoning emphasis and concentrating on the growth of national output. The trend towards tackling poverty, income distribution, and unemployment, thus redefining development in the 1970 s to help reduce poverty and inequality and eliminate unemployment in an economy that continues to grow. Development is not only an economic issue, but also linked to political ideas and Government and the role of the masses in society [5] Development requires a government capable of directing and supporting key economic growth efforts and people who volunteer to work effectively in projects and in their management and other organizations that arise in development work contexts [6].

\section{The environment}

Is a set of policies and procedures taken to Transmission of society to better using the appropriate technical environment setting and taking environmental considerations as a governor and a political factor so as to achieve a balance between the building of natural resources and the destruction of man have lost in the national and international policies to maintain the balance within a specified period of time [7].

Hence the global interest in working hard to wards the requirements of development and industrial progress and the protection of the environment and natural resources and work to reduce the negative effects on the elements of life and resulted from the close link between environment and development to the emergence of the concept of sustainable development and this concept takes into account the conditions of the natural environment and human development work Continuing in various development activities entails reconsidering the absolute dependence on the absorptive capacity that was reflected in the standards set in the past so that consideration can be given to the continuous increase in the neglect of pollution and its impact on the extent Natural standard for absorbing pollutants [8].

\section{Dimensions of development}

It is a process whereby a country uses its available resources to achieve a rapid rate of economic expansion that leads to a steady increase in its national income and per capita goods and services. This development requires gradually overcoming economic constraints and the availability of capital, technical and technological expertise.

Development aims to use natural resources to achieve the economic well-being of the community and the individual.

Social justice is the ultimate goal of human development and the results of economic progress can be used to spread social justice including high human values in all aspects of the globe [9].

\section{Second: section: Human Factors \\ Population growth}

It is worth mentioning in the Islamic Banking Department that the population of the city was (3000) in (1866) as estimated by (2000) by one of the supervisors. This number increased rapidly to reach (10371) people in (1957). Then the number increased to reach (18470) in (1957) and continued this increase to reach (1965) by (34790) people and then to (75489) in (1997) has reached the population of the city (170776) either estimates in (Estimates have been adopted due to the lack of a census in recent years and the population in 2016 has reached (276918) as in Table (1). As shown in Table (2) population to revive the city of Baquba, according to residential neighborhoods for years $(1947-2016)$.

Table-1: Number of residents of the city of Baquba for the period ( 1947-2016)

\begin{tabular}{|l|l|l|l|l|l|l|l|l|}
\hline Census year & 1947 & 1957 & 1965 & 1977 & 1987 & 1997 & 2010 & 2016 \\
\hline population & 10371 & 18470 & 34790 & 75489 & 144052 & 170776 & 228696 & 276918 \\
\hline
\end{tabular}

Source: 1 - Ministry of Planning, Central Statistical Organization the results of the revolutions for the years - $1965-1957-1947$ .1997 - 1987 - 1977Population estimates for .2016-2010 
Table-2: Population of Baquba City Distributed by Residential Neighborhoods for the Years 2009 - 2010 - 2016

\begin{tabular}{|l|l|l|l|l|}
\hline $\mathbf{T}$ & Neighborhood Name & Population 2009 & $\begin{array}{l}\text { Population 2014 } \\
\text { people }\end{array}$ & $\begin{array}{l}\text { Population 2016 } \\
\text { people }\end{array}$ \\
\hline 1 & The first Tekke & 16277 & 19777 & 21390 \\
\hline 2 & The second Tekke & 9193 & 11170 & 12081 \\
\hline 3 & Hittin neighborhood and transformative neighborhood & 7835 & 9520 & 10297 \\
\hline 4 & The Serail & 3765 & 4574 & 4947 \\
\hline 5 & Samarra neighborhood & 3828 & 4651 & 5031 \\
\hline 6 & Al-Obour and Al-Zohour District & 5162 & 6272 & 6784 \\
\hline 7 & Hakim & 2318 & 2816 & 3046 \\
\hline 8 & The neighborhood camp & 3794 & 4609 & 4985 \\
\hline 9 & New Baquba & 12720 & 15455 & 16716 \\
\hline 10 & Salam & 3338 & 4055 & 4386 \\
\hline 11 & Al Mafraq Neighborhood & 9052 & 10998 & 11895 \\
\hline 12 & Yarmouk first and industrial complex & 32966 & 40056 & 43325 \\
\hline 13 & Mehrdar & 634 & 770 & 833 \\
\hline 14 & First Liberation & 30879 & 37520 & 40582 \\
\hline 15 & Tahrir Second neighborhood & 19675 & 23906 & 25857 \\
\hline 16 & Shaftah neighborhood & 7847 & 9534 & 10312 \\
\hline 17 & Teachers' neighborhood & 15296 & 18585 & 20101 \\
\hline 18 & Mustafa neighborhood & 11008 & 13375 & 14791 \\
\hline 19 & Second Yarmouk & 29147 & 35415 & 38305 \\
\hline 20 & Industrial Neighborhood and Umm al-'Amm & 4508 & 5477 & 5924 \\
\hline 21 & Maysaloon neighborhood & 2971 & 3609 & 3903 \\
\hline & Pain masses & 232213 & 282144 & 305491 \\
\hline
\end{tabular}

Source: Population estimates for 2009- 2014- 2016

\section{The third section}

\section{Historical view of solid waste}

Solid waste was the material that accompanied human through the ages and is a source of pollution of the urban environment and consists in the simplest form of food processing waste and ashes resulting from the work of heating, bakeries and kitchens, as well as worn clothes and debris tools and utensils, household furniture and building materials.

As a result of the high population density in urban residential areas, new sources of waste production such as shops, institutes, institutions and factories have been added. It has been impossible to adapt with the accumulation of such wastes within residential areas. Therefore, regular solid waste disposal services have been in existence for over 100 years. Countries that have advanced industrially to prevent their accumulation and in line with public health requirements that have grown in importance at the time. During this period of time, many variables have emerged. The volume has also increased dramatically, and the means of preservation and temporary storage have evolved from a simple open pile to the use of easy-to-carry containers to the development of large containers, as well as the means of transport changed from the use of horses and other animals to cars and from open-top trucks to automatic press.

The negative effects of solid waste are not limited to what causes distortion and ugliness in the landscape, environmental, urban, degradation and public health risks represented by the multiplication of disease vectors (insects and rodents) and risks to the health of workers in collection, transport and disposal, as well as pollution of water, air and soil. An important form of waste if resources are not utilized properly in accordance with the requirements of achieving sustainable development

\section{Definition of solid waste}

According to various studies related to the subject of waste a set of scientific definitions that explain the meaning of waste in its various forms and categories. The study will address some of these definitions in order to reach the comprehensive procedural definition of the term waste or waste. These definitions are as follows:

The term wastes has many labels such as trash and garbage and waste and scrap and thus can be defined as waste material that has become a non-value must be disposed of)) [ 10]. It also known as (all residues from production processes or the conversion or use , and in general all the material and stuff movable discarded holder or intended to be disposed of or that need to get rid of them remove them in order not to damage human health and the environment in general [11]. 
Solid waste is also defined as substances or objects that have not been modified by value or use, but their survival in the environment poses serious dangers to the sources of life in the environment, whether plant, animal or human.

\section{Types of wastes}

There are many categories of solid waste: there are classified as: household waste, commercial waste, industrial waste (hazardous, non-hazardous) medical waste, urban traffic waste.

Waste is usually classified into major groups. The general classification varies in many countries and each category contains secondary categories, but these categories, although multiple, are in the same subject, so the main classification will be mentioned in most of the institutions concerned with solid waste management.

- Domestic solid waste

- Commercial solid wastes

Industrial solid wastes

Medical solid wastes [12]

\section{Waste categories}

The sources from which solid waste is generated have an important role in the management of solid waste. Through these sources, the quantities from which waste is generated can be estimated. The diversity of waste and its characteristics is due to the diversity of waste sources. Therefore, solid waste is classified according to the source of its production to:

Household waste: Household waste is often dependent on the daily activities of the human being, therefore, the economic level and income rate are the main factors in the process of dumping household wastes are constitute the largest proportion in urban areas, accounting for $55 \%-65 \%$ of waste Solid food residues are the main component of household waste as well as varying proportions of (paper, plastic, leather, glass, metals and electronic consumables.

Industrial Wastes: Industrial waste is the waste generated from various industries and put into the environment in the form of solid (solid - liquid - gas) and is of a continuous and varied nature with the diversity of industries such as chemical industries, metallurgy and leather.

Solid Commercial Wastes: Wastes produced from commercial centers such as offices, restaurants, markets, hotels (it is very similar to household waste in terms of quality, but it differs from it in terms of the proportion of components and quantity of waste produced and includes commercial waste from office work) Large quantities of paper and warehouse waste and large quantities of cardboard and packaging cans. Restaurants and markets include a large proportion of remains of food.

\section{Wastes of municipal services}

It is defined as waste collected by municipal establishments and generated from residential houses, shops and government institutions such as schools, hospitals, etc. It also includes garages, spaces, gardens and waste from street sweeping. The main components of municipal waste are paper and cardboard and organic materials such as food residues, garden plants, plastic, Glass, metals and textiles.

\section{Demolition and construction waste}

It is the material resulting from the demolition and construction of structures and buildings, which are inert materials and do not pose a threat to human health, so they can be used in the operations of backfilling and road construction and others. But if they are thrown randomly, they distort the landscape and if they are placed on agricultural land, they will be lost [13].

\section{Solid wastes management in cities}

Solid waste management is usually a complex process because it involves methods and techniques associated with minimizing waste from its sources of generation, storage, collection, transport and final disposal. All these activities and processes should be implemented in accordance with social and environmental laws and regulations that protect the health, the public environment and the aesthetic landscape as well as the economic aspects.

The definition of solid waste management is to control the processes of (generation, storage, collection, transport, treatment, recycling and final disposal) of solid waste in a manner or manner consistent with the standards of public health, economic and urban and regional planning standards, conservation of natural resources and environmental considerations.

It also relies on the public and private sectors alike to find appropriate solutions including administrative, financial, legislative, planning and engineering aspects related to the problems of solid waste and re-addressed these fields many fields of science and knowledge, including: 
Planning, Geography, Public Health and Engineering

In order to design an appropriate waste management system, the following objectives must be achieved:

- Protection of public health

- Achieving high quality urban for environment

- Support the economy

- Providing job opportunities

The concept of integrated solid waste management is an approach or method responsible for failures from conventional solid waste management established and initiated in the United States through the EPA. (EPA) In early 1990 to expand the solid waste management system instead of focusing on waste disposal it also includes prevention and minimization of waste from a minimum source reuse and recycling A social culture is also an institutional environment that effectively affects the sustainability of waste management and relies on long-term strategies.

The main objective of integrated management is to reduce the amount of waste disposed of in landfill sites.

- $\quad$ Promote cooperation between waste producers and waste collectors working in the processing and manufacturing stayes.

- Reduce environmental degradation

- providing the energy and reduce the depletion and conservation of natural resources to classify sustainability

\section{Good waste management}

Integrated solid waste management includes a set of plans and strategies that help achieve its goals and objectives

- $\quad$ Reduce the source

- Recycling

- Waste transportation

- Landfill [14]

\section{Factors affecting on solid waste disposal rate}

When designing any solid waste management system in any city, the quantities of waste should be calculated because it is one of the main factors involved in choosing the type of machinery, the number of workers, the frequency of collection operations, in addition to the method of treatment and final disposal of waste. The above mentioned changes with the change of place and time and different living, economic and social level as well as the geographical location and the seasons of the year represented by changing climatic conditions that affect the frequency of collection and other factors.

It is prevalent to calculate the daily dumping rates per person of waste by weight and is rarely calculated by volume to change the volume during different transport operations and the quality of the machines used while weight remains relatively constant as it was found that the types of mechanisms used in the process of collection and transport differ the volume of waste, for example mechanisms such as open IORRY agricultural tractors have the largest volume of waste which unlike the mechanisms of the type Alcabsat which has technology hydraulic pressing for solid waste are working to reduce the volume of waste in addition to the volume of waste is different except The process of transfers were put forward by the source to intermediate stations that found access to places of treatment and final disposal mismatch exposed to loss during the collection and transfer process or sometimes accidental entry of sorting through the waste collection and transfer. Several methods for calculating the disposal rates of solid waste, which will be mentioned as follows:

\section{Method of calculating weight}

This method is calculated by calculating the weight of the waste collected in mechanisms (vehicles) of known size using this information is reached per capita production of waste after knowing the population of the area from which the waste was collected and the time and density of waste.

\section{The method of quantitative balance between the incoming and outgoing resources}

This is by calculating the amount of materials entering all sources of waste disposal and the amount of materials consumed in it and then put as solid waste. This method is accurate but requires high costs and much information used in some industrial facilities in particular.

\section{Method of weight and size}

By knowing the weight and size of each type of waste component, we give this method more information about the density of solid waste, but it does not give a clear picture of the rate of production of each waste person, except by conducting a complete survey. 
In this study, the method of calculating the rates of per capita disposal of solid waste during the day will be adopted and will be explained in detail in the third chapter, which will explain the rates and quantities offered at the level of the city of Baquba, its sectors and the related processes.

\section{Methods of solid waste treatment in cities}

Here are the ways in which the properties of hazardous solid waste can be changed to make it non-hazardous or less hazardous. It can then be handled more safely and can be transported, collected, stored or disposed of without causing harm to humans and the environment.

Landfill or landfill: Landfill is one of the most common methods of solid waste disposal. Landfill sites must be characterized by special engineering specifications, which rely on solid waste compacting to accommodate the largest amount and to reduce permeability and cover the waste with a clay layer insulating and non- effective. The landfill site should be selected after a geological study of all alternative sites to ensure that the environment is not damaged by the leakage of liquids resulting from the decomposition of waste water to groundwater.

Incineration: This method is one of the most widespread methods in the world in the past years and is done by high-tech incinerators or just open burning in the yards and this method is used for the lack of space available for sanitary landfill. purposes.

Recycling of waste is the recycling of waste after size and sorting to take advantage of some of its components in different

Organic Analysis: - It is the conversion of solid organic waste to organic fertilizers representing an improved material for the characteristics of agricultural soil through organic fermentation or biodegradation and returns the material to its natural cycle.

Solid Waste Management in Baquba

The solid waste management topics are very important in the study area where it was found that in the study area there are two stations where the first in the district teachers and an area of $600 \mathrm{~m} 2$ and serve this station three western sectors, a district teachers inspired Mafraq and Baquba, the new second station is Camp Saad station and an area of $700 \mathrm{~m} 2$ The eastern part of Tahrir and Baquba serve the center and are transported from this station by heavy machinery to landfill sites at the intersection of Kanaan.

This waste is lifted daily by 450 tons of waste in the city of Baquba on two meals per day morning and evening and covers almost $98 \%$ with a lifting efficiency of up to $78 \%$. Places away from the city center are serviced once or twice a week and close to the city center daily.

There is no recycling of waste from intermediate stations to landfill sites and is buried in layers. The most important areas that serve once a week areBab al-Darb area, the role of the camp, Umm al-Kelfar, ten thousand Yarmouk (Rahma) and Mohandiseen and the end of Yarmouk II (Razi).

The total landfill site is 200 Acres and the area currently used is only 16 dunums and is located at the intersection of Canaan tourist. The volume of waste transported to it is 15 tons per day at a rate of 654 tons per week

It is noticeable that there is no waste recycling plant and therefore there is no use of this waste.

\section{Conclusions}

The amount of waste collected by 450 tons of waste in the city of Baquba on two meals per day morning and evening and covers almost $98 \%$ of the lifting efficiency up to $78 \%$

Identify areas that reach services to places far from the city center is served once or twice a week and close to the center daily.

The lack of commitment of most citizens in the city of Baquba proper and safe storage of real waste in addition to the dumping of waste in plots of land and empty real estate and the entrances to the main roads leading to their neighborhoods as a result of delayed collection and transport of waste, which has become almost non-existent in some aspects of the city's neighborhoods, especially housing Consequences of environmental and health damage to the surrounding areas. of Baquba.

The spread of the phenomenon of waste collectors in return for direct wages by the people in most neighborhoods of the city 
The absence of any indicators to apply any of the experiences of the foreign and Arab state successful in the field of solid waste management in the city of Baquba.

The high proportion of organic materials encourages investment in the recycling of these words by converting them into a good organic fertilizer can be used in most agricultural operations.

Although the municipality of Baquba , the establishment of a sanitary landfill south east of the city but it cannot be managed properly in the light ofthe shortfall and the number of cadres specialized mechanisms and thus turn into an open landfill and the resulting damage to various different environmental.

\section{RECOMMENDATIONS}

Campaigns maintenance mechanisms deactivated in the municipality of Baquba by people specialized in this side to contribute to bridging the shortfall number allocated to the operations of hygiene in the city mechanisms.

The need to allocate areas for the construction of maintenance workshops and cleaning machinery and equipment of the municipality permanently to ensure their maintenance until the availability of alternative.

Work on the distribution of bags of waste regularly and permanently on the neighborhoods of the city of Baquba to accommodate the volume of waste from each neighborhood during the day to ensure that the waste is not put on the sides of roads and open areas by the people.

Distribution of containers intended for the collection of waste to residential houses in the neighborhoods of the city of Baquba gradually to ensure the realization of the process of storage of waste in a peaceful and safe manner by the owners of residential houses in addition to facilitating the process of collection and transport of waste.

\section{References}

1. Mohamed, A.W.I. (2003). Guide Rooting and selection of landfills in Yemen, a symposium of recyclable solid waste management and re - use, Benghazi - Libyan masses, 7(1), 1.

2. Abdelkader, A. (2003). Moroccan experience in the field of solid waste management and recycling Symposium on the management of recyclable solid waste and reuse, Benghazi - Libyan masses, 2.

3. Hisham, T.J.K. (2010). Household solid waste in the city of Baquba and the possibility of processing industry Cycle, Master Introduction to theCollege of Education Asmaee, Diyala University, unpublished, S51-55.

4. Saadoun, H.J.R. (2016). Hussein Rida Said and the development of solid waste management systems (Applied Research in the city ofHilla) based search to the Journal of Economic Sciences, 22(91), 131.

5. Saadoun H.R, op. Cit., 134.

6. Mohamed, El, S.A. (1999). Human and Environment, Egyptian Lebanese House, Cairo, 1999, p. 335.

7. Hey. Peter, G.(1975). Meyers ((selection of advanced solild was tedisposal techniques)), jouenal: public work, 70-71.

8. Hey.www.google.geoqassim .org / categories / 2 / researches / 31

9. Baquba Municipality Directorate, Solid Waste Division, unpublished data. 